\title{
Shenxin's Yarn Production System Before the Anti-Japanese War: A Multi-period Analysis
}

\author{
Zhengkun $\operatorname{Sun}^{1} \&$ Xiaoming Yang ${ }^{1}$ \\ ${ }^{1}$ College of Humanities, Donghua University, Shanghai, China \\ Correspondence: Xiaoming Yang, College of Humanities, Donghua University, Songjiang, Shanghai, 201620, \\ China. E-mail: ynide@sina.com
}

Received: July 18, 2019 Accepted: August 13, $2019 \quad$ Online Published: September 29, 2019

doi:10.5539/ass.v15n10p43

URL: https://doi.org/10.5539/ass.v15n10p43

\begin{abstract}
The present study analyses the yarn production of the Shenxin Company across three periods, ranging from the First World War to the eve of the Chinese War of Resistance against Japanese Aggression (the Anti-Japanese War). The study adopts a quantitative method to compare, analyse and discuss the development trends of the company during different stages of history, and explores the changes in yarn production of the members of the Shenxin conglomerate in Hankou, Wuxi and Shanghai in detail. The analysis showed that despite a slowdown in the Chinese economy, Shenxin's cotton spinning and weaving system had managed to exceed its yarn production shares in 1931-1932, indicating that the system coped well with the economic crisis.
\end{abstract}

Keywords: Shenxin Company, the Rong Family, the Textile Industry, National enterprises, enterprises modernisation

The present study uses the data from the Historical Statistics on the Chinese Cotton Spinning Industry compiled by the Shanghai Spinning Industry Association for a multi-period comparison of yarn production of the Shenxin system of cotton spinning industry. A quantitative and comparative analysis of the development trends of the Shenxin Company across different historical periods is made and presented. Further, changes in yarn production of the Shenxin conglomerate members in Hankou, Wuxi and Shanghai are explored in an in-depth analysis.

\section{Analysis and Evaluation of Yarn Production during the Golden Development Period amid the First World War (1915-1922)}

During the First World War (1915-1922), the Shenxin Company in China witnessed stagnation in business and expansion in the scale of Shenxin's Wuxi plant. Table 1 shows that productions across four spinning mills of Shenxin during these two years stagnated. The only exception was a slight growth in the production of Shenxin No. 3 Mill. In 1921, Shanghai mill's yarn production accounted for 13\%, which was slightly higher than that of the spindles that the mill owned among all Shenxin mills. That percentage rose to $12 \%$ in 1924 . Moreover, yarn production of Shenxin No. 1 Mill was higher than in some of the mills with higher numbers of spindles, such as the Hongsheng Mill (23 $320 \mathrm{pcs})$. These results pointed to fairly good business performance of Shenxin during the years. However, it still lagged in some larger-sized mills such as Baocheng No. 1 and No. 2 mills (No.1: 39 600; No. 2: 63 000). Shenxin No. 3 Mill, with a yarn production almost double of that of its former owner, the Zhenxin Mill (13 750 pcs), was arguably the leader compared with its counterparts in Wuxi. By 1924, its production had already tripled that of the Zhenxin Mill (13 750 pcs). In 1922, Shenxin No. 3 Mill accounted for $42 \%$ of all yarn production in Wuxi, which further rose to $48 \%$ in 1924. It was undoubtedly the largest mill in Wuxi in terms of both spinning equipment and yarn production. The mill represented $13 \%$ of all yarn production in Jiangsu in 1922, and the percentage had risen from $2 \%$ to $15 \%$ by 1924 . Therefore, Shenxin No. 3 Mill was the leader in Jiangsu, a province noted for its well-developed cotton spinning industry at the time in China.

Given the diverse nature of yarn production, two years' data were selected for this study, beginning in 1922 when Shenxin No. 4 Mill started operations (Table 1). Owing to the unavailability of data for 1923, data for 1924 were selected. Considering the scale changes for some mills in Hubei Province, such a data selection method may have impacted the percentage of Shenxin No. 4 Mill. However, the magnitude of this impact is controllable, given that the statistical year span was short. Unavailability of data for 1923 and given that the Shenxin No. 4 Mill had not started until 1921 made the 1924 data the best choice. Yarn production of Hankou-based Shenxin No. 4 Mill, which had not been established until 1922, was only 9000 pcs in both the years, making it the 
smallest contributor to Shenxin's yarn production during this period. However, the spinning and weaving industry in Hubei Province was less prosperous and non-comparable to that of Jiangsu. Shenxin No. 4 Mill, remarkably, accounted for $20 \%$ of yarn production in Hubei, which declined to $11 \%$ owing to various reasons in 1924.

Table 1. Cotton Consumption and Yarn and Fabric Production in Different Regions in 1922

\begin{tabular}{ccc}
\hline \multirow{2}{*}{ Region } & 1922 & 1924 \\
\cline { 2 - 3 } & Yarn production (pcs) & Yarn production (pcs) \\
\hline Shanghai (Chinese business) & 359526 & 382333 \\
Juxi & 64450 & 72450 \\
Huangsu & 211310 & 229310 \\
Shenxin No. 1 Mill & 45659 & 84401 \\
Shenxin No. 2 Mill & 24000 & 24000 \\
Shenxin No. 3 Mill & 21000 & 21000 \\
Shenxin No. 4 Mill & 27000 & 35000 \\
\hline
\end{tabular}

Note. Data were derived from Tables 12, 13 and 22 of the Historical Statistics on the Chinese Cotton Spinning Industry compiled by Shanghai Spinning Industry Association in October 1950.

An analysis of the changes in yarn production in Shenxin Company before and after 1922 gives a better understanding of the company's performance during the period. Western powers were deeply engaged in the First World War (July 1914-November 1918), and thus significantly reduced their capital expansion in China. Yarn imports declined by half in 1918, compared with those in 1913. This opened up opportunities for Chinese businessmen to develop the cotton spinning industry. Following the First World War, the Twenty-one Demands and the May Fourth Movement ignited patriotic sentiments among the Chinese who were engaged in a boycott of Japanese goods, leading to another historical opportunity for the development of the enterprises funded by national bourgeoisie capitals. In particular, total yarn imports from Japan to China were 746000 tam in 1918 , accounting for 66\% of China's total yarn imports; however, by 1919, the imports had declined to 531000 tam and 33\%, respectively. The decline in imports of Japanese yarn opened up markets for the development of national enterprises. In addition, yarn prices were relatively higher than the low cotton prices during the period. Huge profits further motivated Chinese mill owners to expand their business scale. Therefore, China's cotton spinning and weaving industry witnessed unprecedented development during this period. Arguably, the growth of Shenxin mills in yarn production was attributable to both the then favourable market conditions and the Rong brothers, who grabbed the historical opportunities and adjusted their strategies accordingly.

\section{Yarn Production of Shenxin Company from 1922 to 1931}

The Shenxin Company had established all of its nine mills by 1931. Given the changing nature of yarn production and that the true production levels of the Shenxin No. 6 Mill were too early to gauge as it was established on November 1931, the study chose data of yarn and cotton fabric production from different regions in 1931 and 1932 (Table 2).

Table 2. Yarn and Fabric Production in 1931 and 1932

\begin{tabular}{ccccc}
\hline \multirow{2}{*}{ Mill } & \multicolumn{3}{c}{1931} & \multicolumn{2}{c}{1932} \\
\cline { 2 - 5 } & Yarn (pcs) & Cotton fabric (bolt) & Yarn (pcs) & Cotton fabric (bolt) \\
\hline Shanghai Huashang Mill & 600440 & 3936206 & 644800 & 4229013 \\
Jiangsu & 313710 & 1690774 & 368439 & 2298510 \\
Wuxi & 111161 & 780086 & 140385 & 1075332 \\
Hubei & 138716 & 1402530 & 180934 & 1484194 \\
Shenxin No. 1 Mill & 20088 & 661852 & 26146 & 735153 \\
Shenxin No. 2 Mill & 24519 & - & 24519 & - \\
Shenxin No. 5 Mill & 16039 & - & 33590 & 323920 \\
Shenxin No. 6 Mill & 4657 & 42593 & 26852 & 328439 \\
Shenxin No. 7 Mill & 25805 & 391844 & & \\
\hline
\end{tabular}




\begin{tabular}{ccccc}
\hline Shenxin No. 8 Mill & 36960 & - & 37977 & 523000 \\
Shenxin No. 9 Mill & 36400 & 512000 & 50600 & 1910512 \\
Shenxin mill in Shanghai & 164468 & 1608289 & 233577 & 476000 \\
Shenxin No. 3 Mill & 16234 & 476000 & 39200 & 297500 \\
Shenxin No. 4 Mill & 16800 & 297500 & 16800 & \\
\hline
\end{tabular}

Note. Data were derived from Tables 2, 3, 7, 8, 48, 49 and 53 of the Historical Statistics on the Chinese Cotton Spinning Industry compiled by Shanghai Spinning Industry Association in October 1950.

Table 2 shows there were no significant changes in yarn production across Shenxin No.1, No. 2, No. 4 , No. 7 and No. 8 mills between 1931 and 1932. However, considerable changes can be found for No. 3, No. 5, No. 6 and No. 9 mills. Among them was the Shenxin No. 6 Mill, which posted the highest growth by about 7.3 times, because it had not started operation until the second half of November in 1931, leading to a 4657 pcs of total production for the year. Comparatively, the No. 9 mill had a relatively longer operational period as it had started production only in the latter part of April, which may explain its relatively lower production growth. The two mills acquired by Shenxin Company in 1931 were operated only for a short period and yielded relatively small volumes of yarn production; therefore, the company only accounted for $27 \%$ of total yarn production in Shanghai during the year. Steady growth was achieved in 1932 (up to 36\%). This is likely because both No. 6 and No. 9 mills had switched to normal operations. However, both the mills still lagged in the percentage of their spindles in 1931. Nonetheless, the ratio of yarn production during these two years had far exceeded that of the previous period (about 13\% on average). In 1931, Shenxin No. 3 Mill accounted for $15 \%$ of all yarn production in Wuxi but only $5 \%$ of that in Jiangsu, whereas the No. 3 mill covered $28 \%$ of all yarn production in Wuxi and $11 \%$ of that in Jiangsu in 1932. The average percentage of yarn production at the No. 3 Mill in Wuxi was about $22 \%$ during the two years, slightly lower than its equipment ratio in Wuxi. Compared with the previous period (45\% on average), the percentage of yarn production of Shenxin No. 3 Mill in Wuxi dropped considerably. Although the production of the No. 4 mill in 1931 was slightly higher than that during the Anti-Japanese War, (12\%), it was 3\% lower on average than that in the previous period.

The production of Shenxin's Shanghai-based mills was rather mediocre in 1931, and many competitors in the region had outdone these mills. The most productive mill was Shenxin No. 8 (36 960 pcs), but competitors such as Yong'an No. 2 and No. 3 mills, Hengfeng Mill, Chongxin Mill and Tongyi Mill exceeded four pcs. The combined production of Shenxin No. 1 and No. 8 mills (57 084) was still the largest. In 1932, yarn production of Shenxin No. 9 Mill alone was 50600 pcs, which was the largest among all Chinese merchant-owned mills in Shanghai. Although Shenxin No. 3 Mill suffered a major decline in yarn production than in the previous period, its position as the largest mill in Wuxi remained. Shenxin's Wuxi-based mills had commanded the largest yarn production in both 1931 and 1932. As a small- to medium-sized enterprise, the Wuhan-based Shenxin No. 4 Mill was less prominent in terms of either production or scale.

Table 2 shows that there was no significant change in the production of fabric plants affiliated to Shenxin mills over the two years. The high production numbers for Shenxin No. 6 Mill is not an exception, though, as it had started operating only later in the year. During the period, fabric plants affiliated to Shenxin's Shanghai-based mills accounted for as much as $41 \%$ of the total production of all Chinese merchant-owned fabric mills in Shanghai, which grew further in 1932 to $45 \%$. In 1932, the overall fabric production in Shanghai slightly increased, and the total production of Shenxin even grew by $4 \%$, which was associated with the normalised production of No. 6 and No. 9 mills. Shenxin's other affiliated fabric plants also grew in fabric production in 1932. The fabric plant affiliated to Shenxin No. 3 Mill represented $61 \%$ of total fabric production in Wuxi and $28 \%$ of that in Jiangsu. Although Shenxin No. 3 Mill did not suffer a decline in fabric production in 1932, the overall production in Wuxi had increased significantly. In 1932, the No. 3 Mill accounted for $44 \%$ of total fabric production in Wuxi, and Shenxin No. 4 Mill covered about $21 \%$ of all fabric production in Hubei, that is, about $1 \%$ higher than that in 1932 .

At this time, the Shenxin Company expanded to nine mills from four and posted substantial growth in yarn and fabric production. Shanghai-based mills presented the most significant growth. In 1931 alone, Shenxin No. 6 and No. 9 Mills had produced about 3.6 times of the yarn than that in the previous period even though both the mills had yet to normalise their operations. In 1932, the production of both the mills was 5.2 times of that in the previous period after their operations were normalised. Shenxin's other subsidiaries also grew during the period, as evidenced by their superior performances in yarn production. Shenxin's Shanghai-based mills also showed greater yarn production in Shanghai than in the previous period. However, despite the growth of spindles at 
Shenxin No. 3 Mill in Wuxi, its yarn production had not substantially increased than in the previous period. In 1931 alone, the mill's yarn production was lower than that of 1922 and 1924, that is, less than half of the production in 1924. Clearly, production declined significantly than in the previous period. As a relatively smaller-sized plant, Shenxin No. 4 Mill showed higher productivity growth. However, compared with the growth of the entire spinning industry in Hubei, the percentage of yarn production by Shenxin No. 4 Mill in Hubei even slightly declined. Similarly, considerable good results were seen in Shenxin's total fabric production. In particular, Shenxin No. 3 Mill accounted for as much as $61 \%$ of the total fabric production in Wuxi in 1931. The number of fabric plants affiliated to Shenxin's Shanghai-based mills also accounted for half of such factories in the city. Even fabric production of the affiliated plant of Shenxin No. 4 Mill, a moderately sized mill, accounted for about $20 \%$ of total production in Hubei.

The increase in Shenxin's yarn production was attributable to its equipment augmentation. During the period, the comparative changes in production were associated with the equipment brought into production. In addition, production growth in fabric plants affiliated to Shenxin's mills suggests that the company had already recognised the importance of a complete industrial chain. The company's sophisticated industrial chain significantly reduced its operational cost and increased its anti-cycle capability on the one hand, and increased its reliance on the spinning and weaving industry on the other.

\section{Yarn Production During the Tough Development Period Before the Anti-Japanese War (1932-1936)}

By 1936, the situation in China eased. A few new machines were installed in Shenxin No. 9 Mill, and Commonweal Iron Works, the equipment building factory whose products were piloted by Shenxin No. 3 Mill, was expanded.

Owing to China's economic recession in 1935, the data from 1935 and 1936 before the breakout of the Anti-Japanese War was selected for the convenience of comparison.

Table 3. Yarn and Fabric Production in 1935 and 1936

\begin{tabular}{ccccc}
\hline \multirow{2}{*}{ Mill } & \multicolumn{3}{c}{1935} & \multicolumn{2}{c}{1936} \\
\cline { 2 - 5 } & $\begin{array}{c}\text { Yarn production } \\
(\mathrm{pcs})\end{array}$ & $\begin{array}{c}\text { Fabric production } \\
(1 \text { 000 square yards })\end{array}$ & $\begin{array}{c}\text { Yarn production } \\
(\mathrm{pcs})\end{array}$ & $\begin{array}{c}\text { Fabric production } \\
\text { (1 000 square yards })\end{array}$ \\
\hline Shanghai Huashang Mill & 555358 & 134281 & 541999 & 152211 \\
Jiangsu & 377198 & 138190 & 404826 & 172223 \\
Wuxi & 159635 & 66864 & 156299 & 77058 \\
Hubei & 107863 & 29033 & 101223 & 27018 \\
Shenxin No. 1 Mill & 44822 & 25572 & 48952 & 33641 \\
Shenxin No. 2 Mill & - & - & 3909 & - \\
Shenxin No. 5 Mill & - & - & 2500 & - \\
Shenxin No. 6 Mill & 34286 & 9101 & 41057 & 11675 \\
Shenxin No. 7 Mill & 30418 & 12347 & 31271 & 13464 \\
Shenxin No. 8 Mill & 37692 & - & 39049 & 12859 \\
Shenxin No. 9 Mill & 48789 & 13655 & 55201 & 71639 \\
Shenxin mill in Shanghai & 196007 & 60675 & 221939 & 37191 \\
Shenxin No. 3 Mill & 52276 & 29093 & 57693 & 17636 \\
Shenxin No. 4 Mill & 30767 & 13071 & 37090 & \\
\hline
\end{tabular}

According to the data of Tables 2 and 3, the total yarn production in Shanghai was 644800 pcs in 1932, which declined to 555358 pcs in 1935 and 541999 pcs in 1936, which is lower than that of 1935. This indicates a substantial overall decline in production. The yarn production of Shenxin's Shanghai-based mills was 233577 pcs in 1932, which declined to 196007 pcs in 1935. Despite a slight economic recovery in 1936, the overall yarn production in Shanghai remained unchanged, but the production of Shenxin's Shanghai-based mills managed to increase to 221939 pcs. Production in 1935 was associated with the suspension of No. 2 and No. 5 mills and the lower operating rate of other mills. As the economy moderately recovered in 1936, Shenxin No. 2 and No. 5 Mills also prepared to resume production after October 1936, a decision that yielded substantial growth of yarn production up to 221939 pcs. The overall yarn production in Wuxi and Jiangsu was not significantly influenced by the economic crisis and showed slight growth during the period. There was significant production growth in 
Shenxin No. 3 Mill, which is likely due to its proper management and moderately improved equipment. The yarn production of Hubei Province in 1935 and 1936 also declined in comparison with that in the previous period. However, Shenxin No. 4 Mill also managed to achieve substantial production growth due to improved management and equipment after a fire incident.

In 1936, Shenxin's Shanghai-based mills had maintained a considerably good production capacity. The yarn production of Shenxin No. 1, No. 6 and No. 9 mills all exceeded 40000 pcs, exceeding that of their competitors in Shanghai. In particular, the production of Shenxin No. 9 and No. 1 mills was 55201 pcs and 48925 pcs, respectively. Comparatively, the highest production of Shanghai-based mills owned by competitors was only around 30000 pcs, much lower than that in Shenxin mills. Shenxin No. 3 Mill reached a production of 57693 pcs, far exceeding that of the Shenxin No. 9 Mill, the largest cotton spinning factory in Shanghai. The only comparable mill in Wuxi was Qingfeng Mill, while other mills, with production less than 30000 pcs, lagged Shenxin No. 3 Mill. Shenxin No. 4 Mill showed significant production growth, which more than doubled its production to become a leading yarn manufacturer in Hubei. With the only exception of Yuhua Mill (41 977 pcs), no other Hubei-based mills were comparable to Shenxin No. 4 Mill.

According to Table 3, Shenxin's Shanghai-based mills accounted for 35\% of the total yarn production of the city in 1935 , which further increased to $41 \%$ in 1936. Although the entire cotton spinning and weaving industry declined during this period, Shenxin Company still managed to grow its yarn production. Compared with the $27 \%$ share secured by Shenxin in 1931, the company's percentage of production rose to $36 \%$ in 1932 . In 1935, the company still managed to achieve a 35\% share despite two suspended mills and lower operating rates in other mills. The share in 1936 was $14 \%$ higher than that in 1931, significantly higher than its equipment ratio in Shanghai. The percentages of Shenxin No. 3 Mill in the total yarn production of Wuxi were 33\% in 1935 and 37\% in 1936, higher than those of the previous period but lower than the period around the First World War in 1922. Production shares of Shenxin No. 3 Mill were $42 \%$ in 1922 and 48\% in 1924, both higher than the capacities of 1935 and 1936. This is also a consequence of the unsophisticated development of mills in the region around the First World War. The yarn production shares of Shenxin No. 4 Mill in Hubei were 29\% in 1935 and 37\% in 1936. The mill's 1931 production was higher than that before the First World War, which only accounted for $12 \%$ of all production in the province. The expansion of the No. 4 mill and the declining spinning industry across the country are important reasons for the significantly higher production shares of Shenxin No. 4 Mill in Hubei in 1935 and 1936 than in the previous period.

Table 3 shows that the fabric plants affiliated to Shenxin's Shanghai-based mills accounted for $45 \%$ of all fabric production in Shanghai in 1935, showing no significant difference from the $47 \%$ share in 1936. Statistically, the data of these two years exceed those of 1931; and the share in 1936 was $2 \%$ higher than that in 1932, similarly as in 1935. Shenxin No. 3 Mill accounted for $44 \%$ and 48\% of total fabric production in Wuxi in 1935 and 1936, respectively. Shenxin's 1935 fabric production share in Wuxi was similar to that in 1932, both lower than that in 1931. Shenxin No. 4 Mill accounted for $45 \%$ of all fabric production by Hubei-based affiliated fabric plants in 1935, which rose to a staggering $65 \%$ level in 1936 .

The fabric plant established by Shenxin No. 1 Mill commanded the largest fabric production among all similar factories, reaching 33641 square yards. That was followed by Yong'an No. 1 Mill, whose production was 20661 square yards, far lower than Shenxin No. 1 Mill. In addition, the production of all Shenxin's four mills capable of manufacturing fabric exceeded 10000 square yards. In particular, fabric production of Shenxin No. 3 Mill and Qingfeng Mill was 37191 and 20245 square yards. By all measures, Shenxin No. 3 Mill was virtually the largest fabric producer in Wuxi. Shenxin No. 4 Mill produced 17636 square yards of fabric, making it the only fabric producer exceeding the 10000 threshold in Hubei.

Despite the devastated Chinese economy, especially the spinning and weaving industry during this period and the fire accident suffered by Shenxin No. 4 Mill, the Shenxin Company had not only managed to rebuild its No.4 mill but also expanded its other mills. However, the development of Shenxin mills was compromised due to over indebtedness of their parent company, which led to No. 1, No. 8, No. 2 and No. 5 mills being controlled by syndicates. In 1935, Shenxin No. 2 and No. 5 mills also suffered from suspended operations because of industry-wide problems, and the operating rate of other mills was also impeded. Although the company's Shanghai-based mills reached a rather mediocre production in 1935, their original capacities were almost completely restored by 1936, and the company would have exceeded its 1932 production level, which was hindered by the late production resumption in its No. 2 and No. 5 mills. The company's shares of yarn and fabric production were notably high in all the regions and enjoyed moderate growth than during the previous periods. Indeed, the capacity of Shenxin No. 3 Mill had slightly increased instead of being affected by the economic crisis, and its production share in Wuxi was also quite impressive. With a previously moderate size and 
production, Shenxin No. 4 Mill managed to grow substantially in terms of total production and shares in 1935 and 1936, which was closely related to the renovated workshops and equipment following the fire.

Business operations of Shenxin Company were quite unsteady during this period owing to influences of the external market. Owing to the relocation of the company's No. 9 mill, the fire of its No. 4 mill and indebtedness of the parent company, Shenxin's No. 1, No. 8, No. 2 and No. 5 were all controlled by syndicates. These syndicate-controlled mills suspended operations in February 1935. The depressed market, lower yarn prices and recessed economy at that time forced the Shenxin Company to seek survival in adversities. The year 1935 represented the most volatile year for China's economy. As a leading industry in China, the cotton spinning and weaving industry was significantly affected by the economic downturn. All Shenxin mills had suffered a decline in production in 1935 .

\section{Conclusion}

The presents study presents a multi-period analysis of the Shenxin's cotton spinning and weaving industrial system before the Anti-Japanese War, which includes the analysis and evaluation of yarn production during the golden period of development amid the First World War (1915-1922), yarn production of Shenxin Company during its expansion period (1922-1931) and yarn production during the tough development period before the Anti-Japanese War (1932-1936). The former two periods had witnessed Shenxin's cotton spinning industrial system gaining substantial growth, given the factors such as the boycott of Japanese goods after the First World War. During the tough development period before the Anti-Japanese War, the company's development was slowed down by a stagnated national economy. Despite the adverse environment, Shenxin's cotton spinning and weaving system had managed to exceed its yarn production shares in 1931-1932, indicating that the system was quite cautious in dealing with the economic crisis. The successful survival of the company itself has sufficiently proved its comprehensive strengths.

In addition, not only had Shenxin's cotton spinning and weaving system improved its overall strengths, but its mills had also increased their production across different periods. While the company still occupied a medium or upper position in terms of yarn production among all Shanghai-based producers, its No.1, No. 6 and No. 9 mills emerged to be leading yarn manufacturers during the tough development period before the breakout of the Anti-Japanese War.

\section{References}

Gong, Y., \& Ru, B. (1940). A Survey of Shenxin No. 2 Mil. Spinning, Weaving and Dying Quarterly.

Rong, D. (2001). Self-compiled Chronicles of Lenong. Shanghai Classics Publishing House.

Shanghai Academy of Social Sciences. (1980). Family Rong's Business History Data (Vol. 1). Shanghai People Press.

Shanghai Spinning Industry Association. (1950). Historical Statistics on the Chinese Cotton Spinning Industry. Shanghai Spinning Industry Association.

\section{Copyrights}

Copyright for this article is retained by the author(s), with first publication rights granted to the journal.

This is an open-access article distributed under the terms and conditions of the Creative Commons Attribution license (http://creativecommons.org/licenses/by/4.0/). 